\title{
Management of intrathoracic tracheal stenosis: a challenge
}

\author{
Nilam U. Sathe*, Anup Srinivas, Saad Ahmed and Rajat Magdum
}

\begin{abstract}
Background: Tracheal stenosis is a complicated surgical problem, which because of endoscopic techniques can be managed by less invasive procedures. In our case series of three patients with intrathoracic tracheal stenosis following prolonged use of tracheostomy tube, we describe the initial assessment, investigations, management, and post-operative results of the same. In our series, all three patients were tracheostomised (with a metallic tube) for more than 3 months. This resulted in chronic abrasion of intraluminal tracheal mucosa at thoracic level. We managed them with conservative trans-oral and trans-tracheal laser-assisted release instead of open surgeries like trachea-tracheal resection and anastomosis or Crico-tracheal resection and anastomosis.

Results: In our case series, we chose transoral bronchoscopic fibre laser-assisted release followed by dilatation for one patient and trans-tracheal release for the other two. In the trans-oral case, we faced difficulty in controlling the long length of instruments, thereby effecting the control over the laser tip and precision of cut. During the revision surgery for the same patient, we faced difficulty in securing the airway below the stenosis as it was a low stenosis. In patients 2 and 3, we approached the stenosis site via tracheostomy site, thereby significantly reducing the working length of instruments. This gave us better control over the instruments and we attained better precision in radial incisions. Moreover, if there had been an intraoperative bleeding or aspiration, we could have easily secured the airway by FROVA as distance between stoma and stenosis site was not very long.

Conclusion: $\mathrm{CO}_{2}$ Lase-assisted stenosis release has a very promising result in up to grade III thoracic tracheal stenosis. A good preplanning with anaesthetists and cardiothoracic surgeons for tailor made approach is a must. Intermittent apnoea technique of anaesthesia really helps in such cases of intrathoracic tracheal stenosis. We advocate to always use soft material tracheostomy tube to prevent mucosal abrasion, to avoid a low tracheostomy without appropriate and to proper fix the tracheostomy tube and try for early decannulation.
\end{abstract}

Keywords: Intrathotaccic trachea, Stenosis

\section{Background}

Trachea is divided into cervical and thoracic parts by the superior border of manubrium sternum. Cervical tracheal stenosis (2nd tracheal ring) is the most common site of tracheal stenosis, usually due to intubation injury or tracheostomy site trauma [1]. In such cases, despite taking measures to prevent post-intubation injury, tracheal stenosis is seen. This is because of overinflation

\footnotetext{
*Correspondence: drneelam_s@yahoo.co.in

Department of ENT \& Head \& Neck surgery, Seth G. S. Medical College \&

KEM Hospital, Mumbai 400012, Maharashtra, India
}

of nonelastic plastic cuffs or leverage on tracheostomy tubes [2].

In our series, all three patients were tracheostomised (with a metallic tube) for more than 3 months. This resulted in chronic abrasion of intraluminal tracheal mucosa at thoracic level. We managed them with conservative trans oral and trans-tracheal laser-assisted release instead of open surgeries like trachea-tracheal resection and anastomosis or Crico-tracheal resection and anastomosis.
Springer Open

(c) The Author(s) 2022. Open Access This article is licensed under a Creative Commons Attribution 4.0 International License, which permits use, sharing, adaptation, distribution and reproduction in any medium or format, as long as you give appropriate credit to the original author(s) and the source, provide a link to the Creative Commons licence, and indicate if changes were made. The images or other third party material in this article are included in the article's Creative Commons licence, unless indicated otherwise in a credit line to the material. If material is not included in the article's Creative Commons licence and your intended use is not permitted by statutory regulation or exceeds the permitted use, you will need to obtain permission directly from the copyright holder. To view a copy of this licence, visit http://creativecommons.org/licenses/by/4.0/. 


\section{Methods}

\section{Patient assessment}

All three patients were seen in the outpatient department of a tertiary care hospital. All three were males aged 26, 28, and 30 years. The three of them had a similar past history of being intubated following head injury with 7-mm endotracheal tube. Tracheostomy was done on days 16,18 , and 16 ,

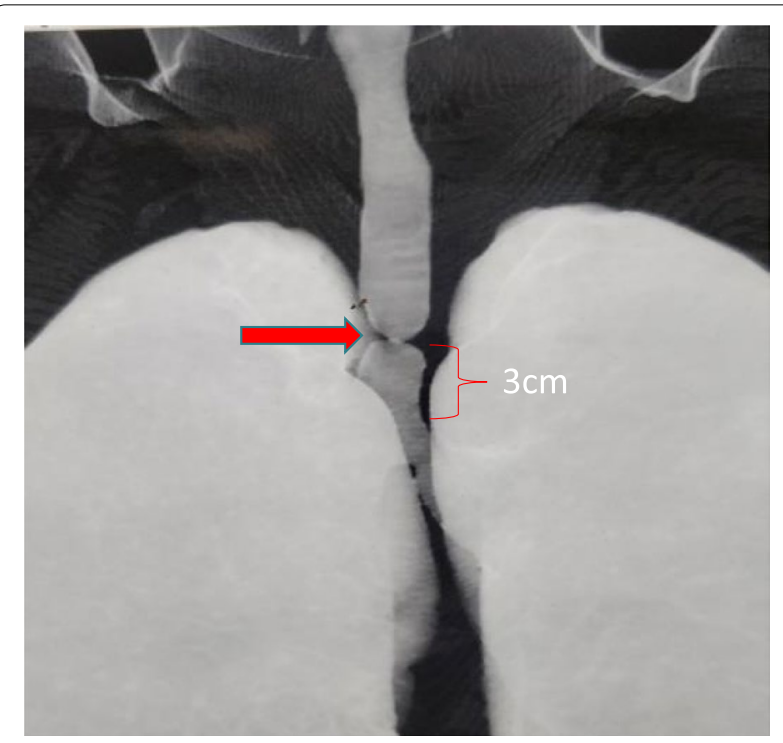

Fig. 1 The intrathoracic tracheal stenosis (grades II-III) about $3 \mathrm{~cm}$ above the carina respectively, with a mean duration of intubation of 16.33 days. The level of tracheostomy for all three was 4-5th ring. They were discharged with a Chevalier-Jackson metal tracheostomy tube in situ of size 28,28 , and 30 , respectively.

Patient 1 was decannulated after 2 weeks while patients 2 and 3 had the tracheostomy tube in place when they presented to us. All three patients presented to us with an average of 3 months of tracheostomy in situ. They had complains of difficulty in breathing and noisy breathing. On examination, they were in biphasic stridor.

Laryngoscopy was done which revealed normal larynx up to the subglottic level. Computed tomography with virtual bronchoscopy reconstruction revealed tracheal stenosis (grades II-III) about $3 \mathrm{~cm}$ above the carina (Fig. 1). The stenosis portion was redesigned on 3D paint software to attain a 3-dimensional orientation (Fig. 2). For further assessment of the stenosis segment, its level, length, and thickness, all three patients were subjected to a $0^{\circ}$ Hopkin telescopic examination under general anaesthesia using the intermittent apnoea technique. All three patients had the stenosis portion was redesigned on 3D paint software to attain a 3-dimensional orientation [3] (Fig. 3). The management of each of the three scenarios is discussed ahead.

\section{Case presentation}

Patient 1

A 30-year-old man presented to us after undergoing decannulation 12 weeks ago. After the assessment of

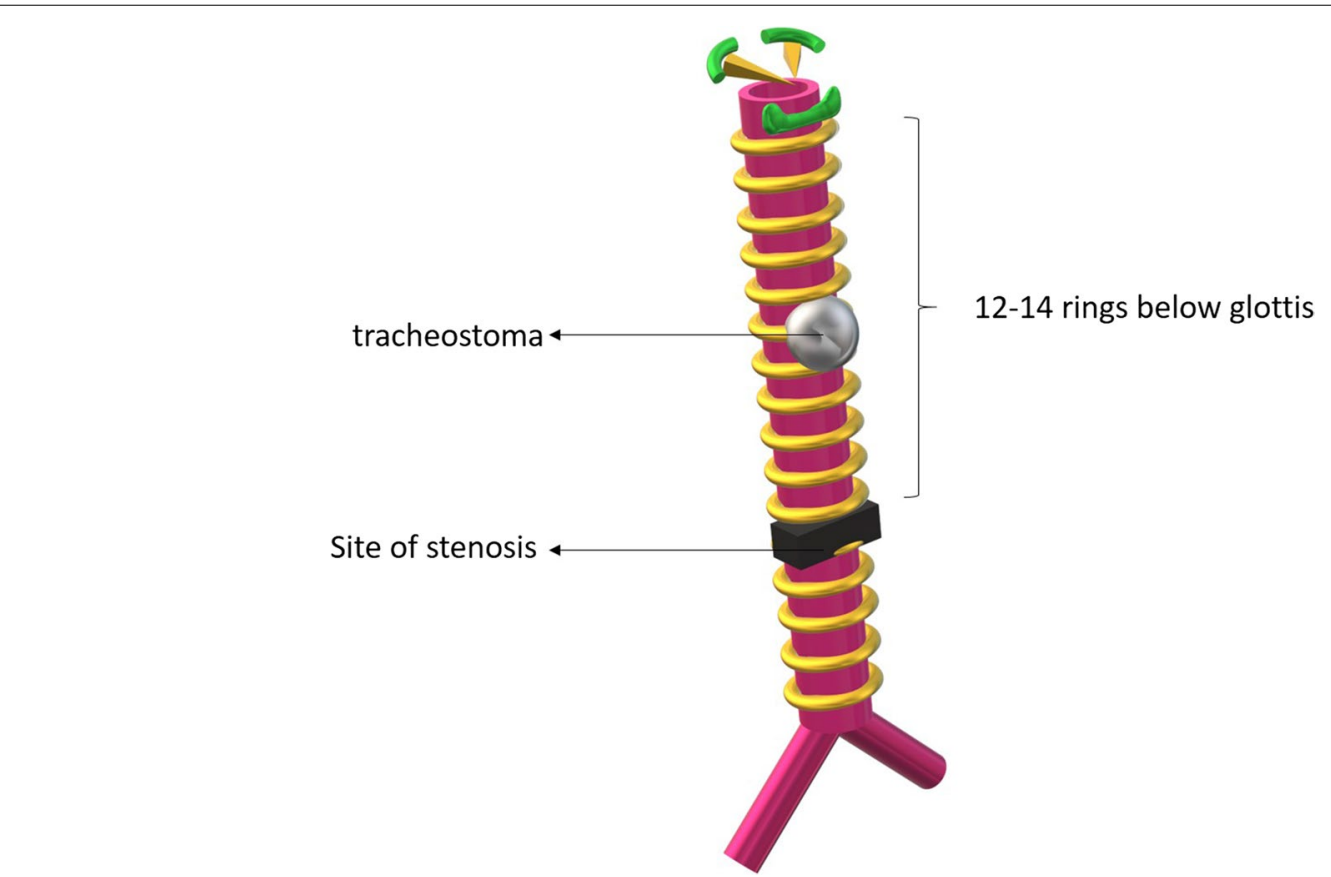

Fig. 2 The stenosis portion redesigned on 3D paint software to attain a 3-dimensional orientation 


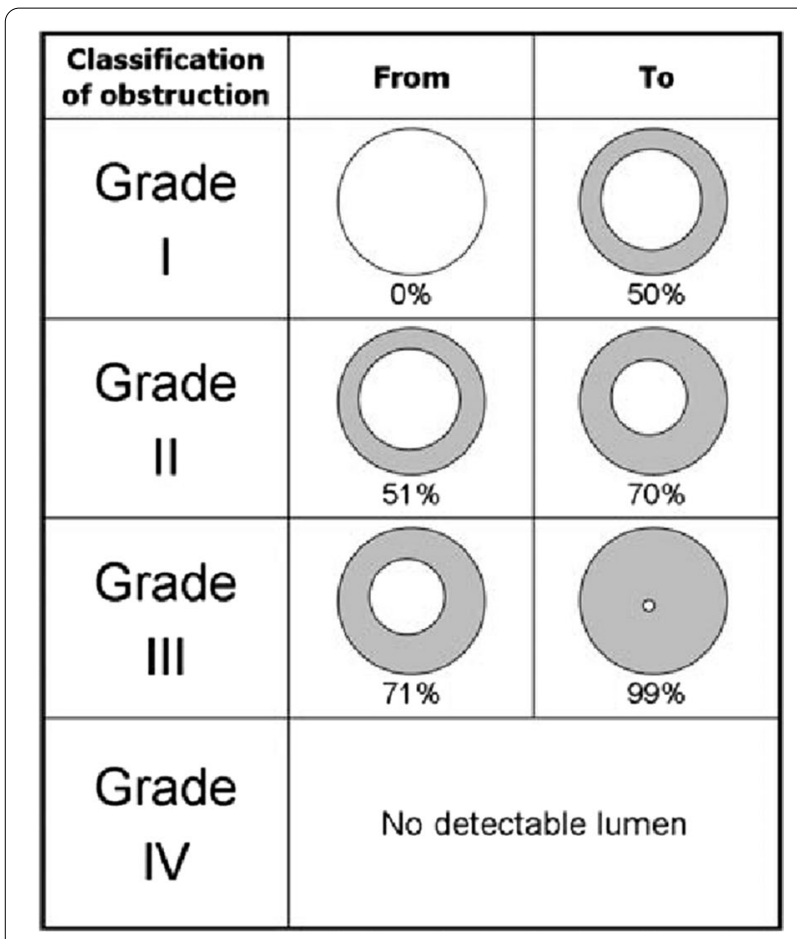

Fig. 3 The complex type both hard and soft components with grade II-II stenosis (Cotton-Myer classification)

stenosis Fig. 8a, he was taken up for surgery. A 7.5-mm rigid bronchoscope was introduced trans orally along with a 4-mm $0^{\circ}$ Hopkin telescope, and the $\mathrm{CO}_{2}$ laser was used to release the stenosis. Radial incisions were given in the Mercedes Benz (Fig. 4), using 2.5-mm Acupulse Fibrelase HP-R 240-mm bent handle with straight tip $\mathrm{CO}_{2}$ fiber delivery system (Laser Machine details). Following the laser release, the stenotic area was dilated by means of serially increasing sizes of bougies. The whole procedure was performed using intermittent apnoea technique, and the setup is shown in Fig. 5 and schematically represented in Fig. 6.

\section{Patients 2 and 3}

Twenty-eight- and 16-year-old men had presented to us with stridor with metallic tracheostomy tubes in situ. Their tracheostomy tube was replaced with a soft silicone tube of same size, and a swab from local site was sent. Based on the culture and sensitivity report, intravenous antibiotics were given while the assessment of stenosis was carried on (Figs. 9a and 10a).

In both cases, the stenosis was addressed via the tracheal stoma (Fig. 7). $0^{\circ}$ Hopkin telescope and Acupulse fiberlase HP-R $140-\mathrm{mm}$ bent handle with straight tip $\mathrm{CO}_{2}$ fiber delivery system were simultaneously introduced via the stoma. The procedure was carried out

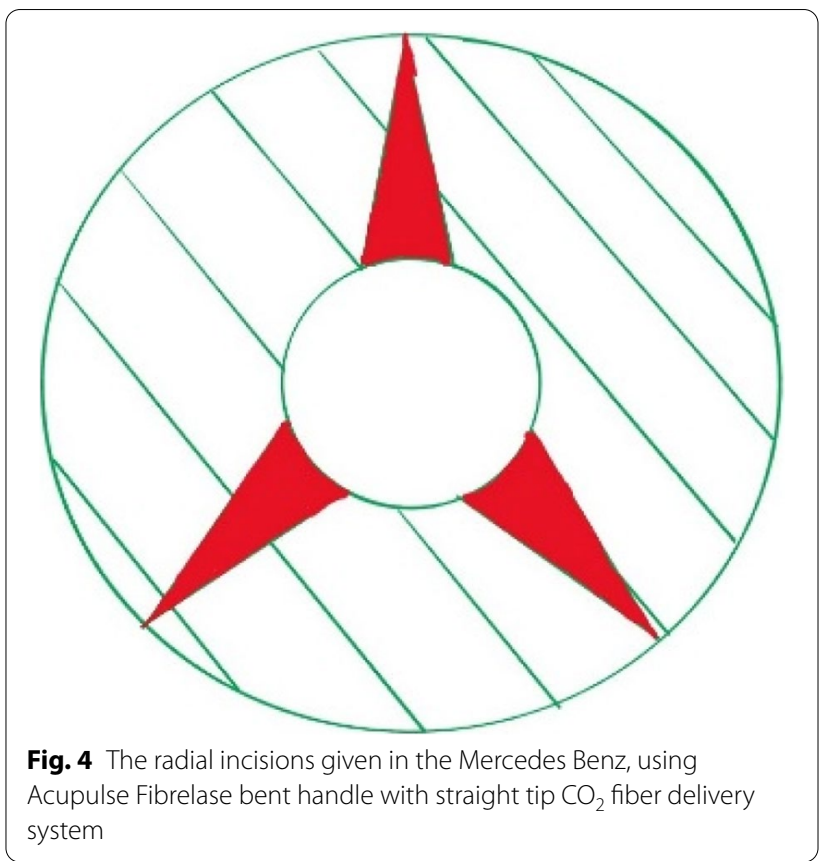

under general anaesthesia using the intermittent apnoea technique (My video 1). Radial incisions were given in Mercedes Benz pattern followed by dilatation by serial size bougies.

\section{Post-operative course}

Patient 1 was found to have developed grade III stenosis during his 3-month-follow-up period. Repeat dilatation was planned but unfortunately he succumbed due to

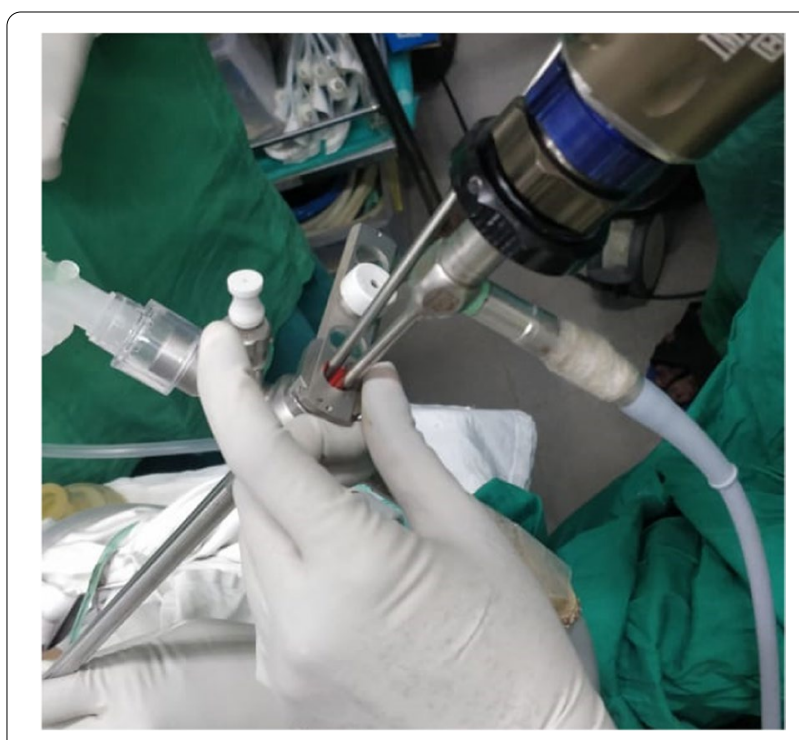

Fig. 5 The intermittent apnoea technique and the setup 


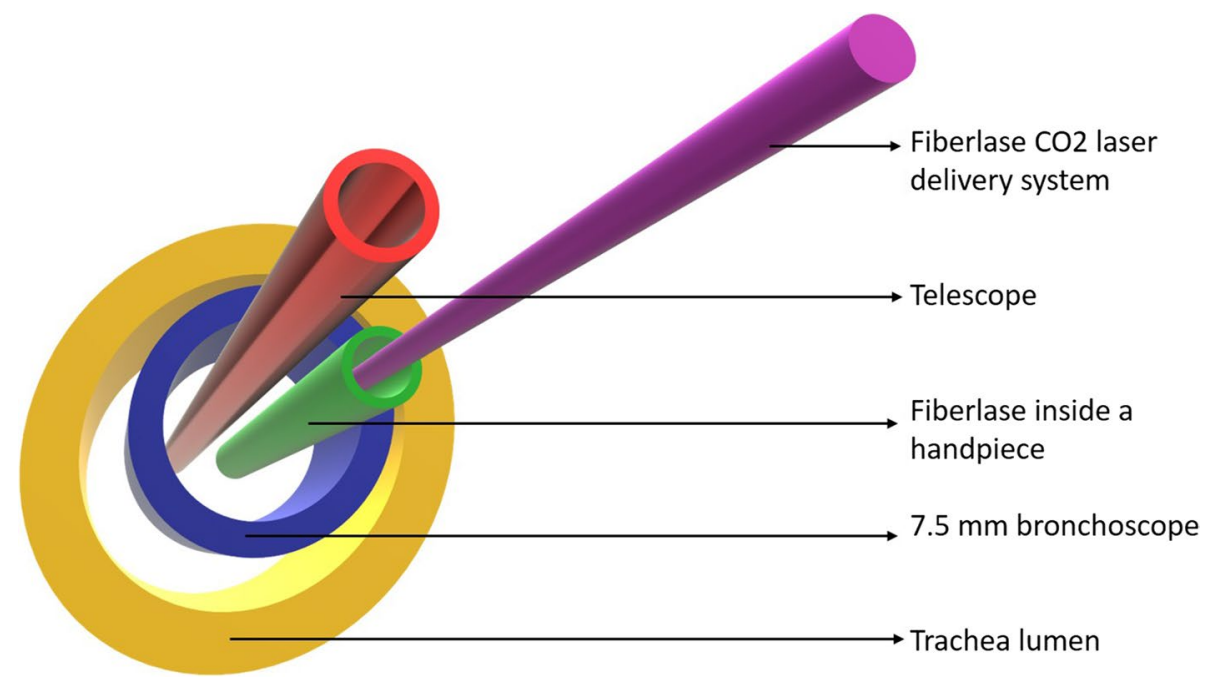

Fig. 6 The schematic representation of intermittent apnoea technique and laser dilatation of the trachea

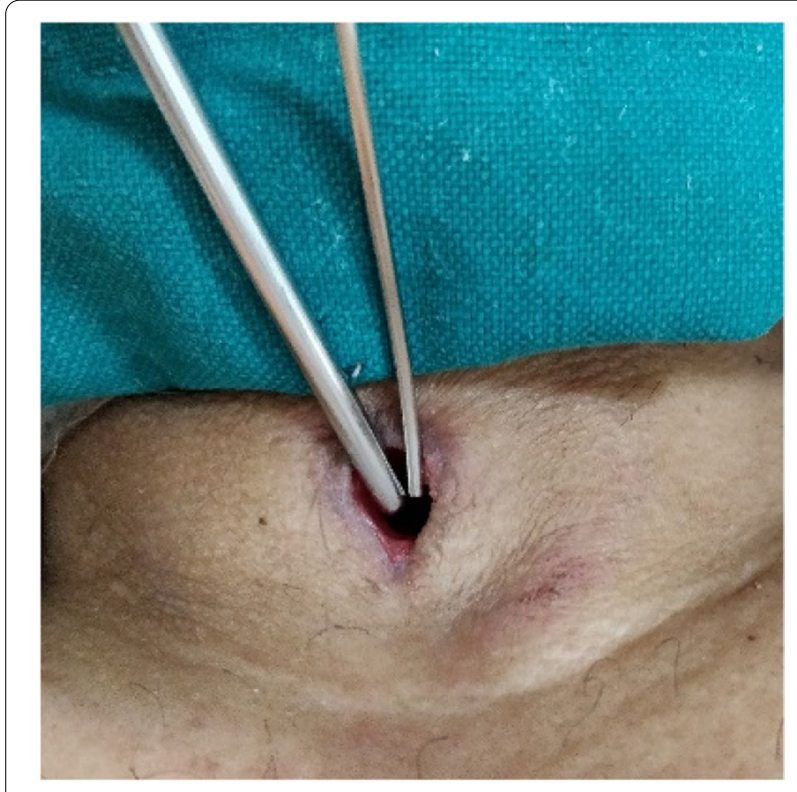

Fig. 7 The stenosis addressed via the tracheal stoma sudden cardiac arrest due to inadequate ventilation. But he got revived successfully.

Patients 2 and 3 were decannulated after the stenosis incision and dilatation and were discharged after 7 days of observation (Table 1). They were followed-up for airway assessment using a flexible bronchoscope under general anaesthesia every 3 months for 1 year. They had developed grade I stenosis with no clinical symptoms and are doing well (Figs. 8b, 9b, and 10b).

\section{Results}

Table 1

\section{Discussion}

The use of endotracheal and tracheostomy tubes is the most common cause for tracheal stenosis, ranging from 6 to $21 \%$ and 0.6 to $21 \%$, respectively [4]. Most of these stenosis are located in the upper (cervical) trachea. The usual sites for tracheostomy-associated tracheal stenosis are stomal site, tracheostomy tube genu, cuff, and the tip region [5].

Iatrogenic thoracic tracheal stenosis is not a common entity. A study by Pearson et al. [6] conducted in Toronto University had a total of 25 strictures in 24 individuals

Table 1 Stenosis incision and dilatation results

\begin{tabular}{|c|c|c|c|c|c|c|}
\hline Approach & No. of cases & $\begin{array}{l}\text { Tracheostomy } \\
\text { status at } \\
\text { presentation }\end{array}$ & Laser type & Handpiece length & Repeat dilatation & Result \\
\hline Transoral & 1 & Decannulated & $\begin{array}{l}\mathrm{CO}_{2} \text { laser fiberlase delivery } \\
\text { system }\end{array}$ & $240 \mathrm{~mm}$ & Once & Recovered without stenosis \\
\hline Transtracheal & 2 & In situ at $4-5$ th ring & $\begin{array}{l}\mathrm{CO}_{2} \text { laser fiberlase delivery } \\
\text { system }\end{array}$ & $140 \mathrm{~mm}$ & None & Grade 1 stenosis \\
\hline
\end{tabular}



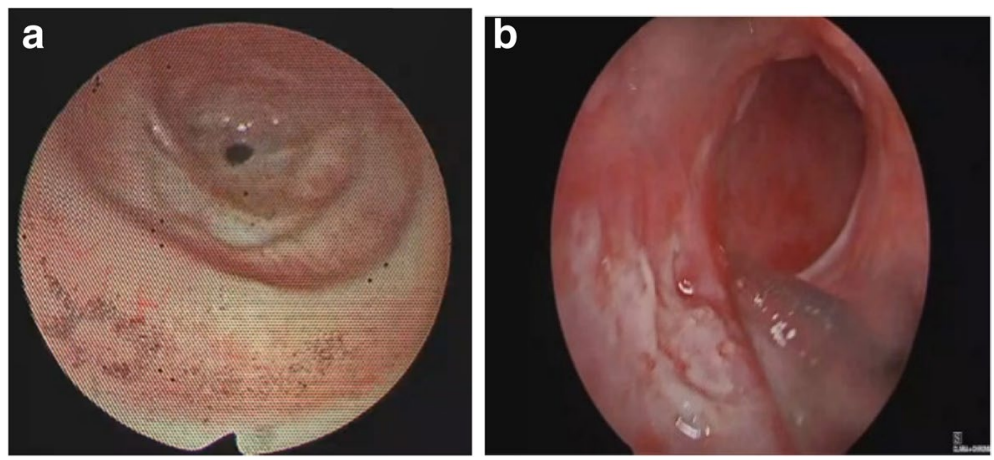

Fig. 8 a Preoperative intrathoracic tracheal stenosis in patient 1. b Postoperative tracheal lumen in patient 1

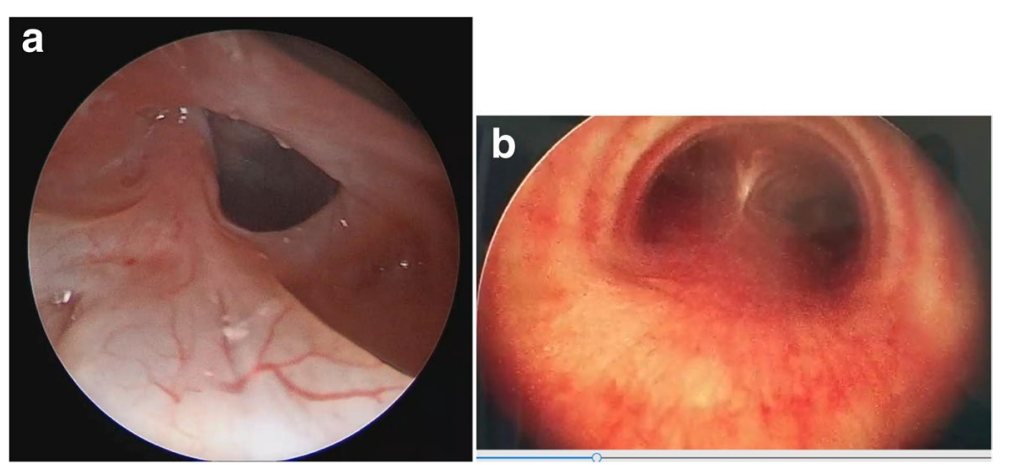

Fig. 9 a Preoperative intrathoracic tracheal stenosisin patient 2. b Postoperative tracheal lumen patient 2

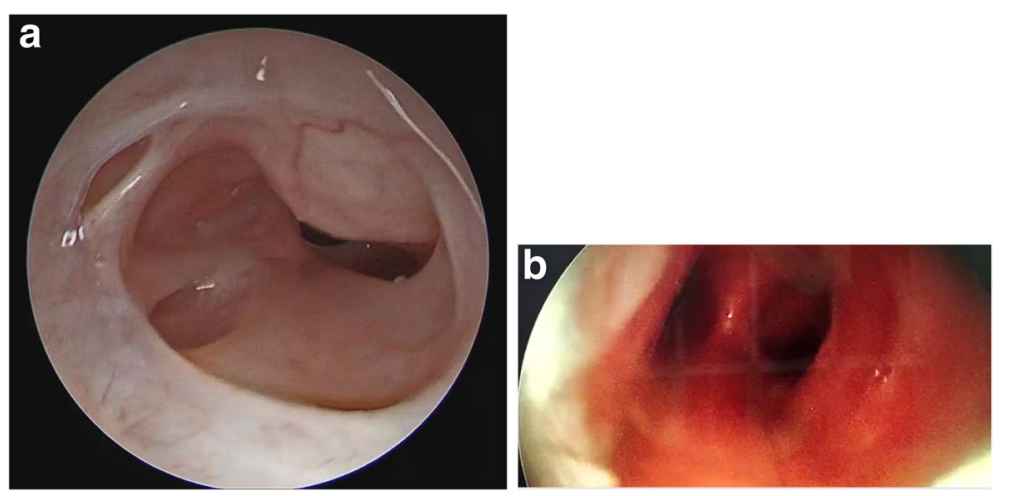

Fig. 10 a Preoperative intrathoracic tracheal stenosis in patient 3. b Postoperative tracheal lumen in patient 3

in 8 years. Out of these, 18 occurred in the cervical trachea and 7 occurred in thoracic trachea at the level of the inflatable cuff. Another study by Galluccio et al. [7] described the management of 209 cases of tracheal stenosis over a period of 10 years. Amongst these stenoses, 21 were in the subglottis, 178 in the upper trachea, and only 10 in the mid/lower trachea. We found no other studies which described more than 3 cases of intrathoracic tracheal.

As stenosis of thoracic trachea is not a common entity, there are no fixed guidelines for their management. The management of tracheal stenosis in general is highly controversial with respect to open surgical techniques vs endoscopic procedures. Earlier, open surgical approaches with end-to-end anastomosis were 
considered as treatment of choice with a success rate of more than $90 \%$, failure rate of $5-15 \%$, and mortality rate up to 5\% [2]. With the use of endoscope, an alternative and less invasive approach to tracheal stenosis was proposed.

Over the years, various endoscopic and open techniques have been proposed such as serial dilatation with rigid bronchoscope [8], bronchoscopic angioplastic balloon dilatation [9], Mercedes Benz radial incision over tracheal stenosis [10], placement of endoprostheses [11] thorarcotomy with tracheotracheal resection anastomosis [12], under femorofemoral cardiopulmonary bypass [13], and sliding tracheoplasty [14].

In our case series, we chose transoral bronchoscopic fiber laser-assisted release followed by dilatation for one patient and trans-tracheal release for the other two. In the trans-oral case, we faced difficulty in controlling the long length of instruments, thereby effecting the control over the laser tip and precision of cut. During the revision surgery for the same patient, we faced difficulty in securing the airway below the stenosis as it was a low stenosis. The preferred option for him was to do a femorofemoral cardiopulmonary bypass. Due to intraoperative bleeding while releasing the stenosis, we were unable to secure airway using FROVA intubating introducer connected to jet ventilation technique and patient had intraoperative cardiac arrest. After cardiorespiratory resuscitation patient came out of the arrest and now absolutely fine. In patients 2 and 3 , we approached the stenosis site via tracheostomy site, thereby significantly reducing the working length of instruments. This gave us better control over the instruments and we attained better precision in radial incisions. Moreover, if there had been an intraoperative bleeding or aspiration, we could have easily secured the airway by FROVA as distance between stoma and stenosis site was not very long.

\section{Conclusions}

$\mathrm{CO}_{2}$ laser-assisted stenosis release has a very promising result in up to grade III thoracic tracheal stenosis. Tracheostomy when performed in such cases reduces the work length from stenosis site for better control of instruments and better post-operative results. A good preplanning with anaesthetists and cardiothoracic surgeons for tailor made approach is a must. Intermittent apnoea technique of anaesthesia really helps in such cases of intrathoracic tracheal stenosis. It also avoids major procedure of heart lung bypass. And hence, there are less postoperative morbidity and mortality. We advocate to always use soft material tracheostomy tube to prevent mucosal abrasion, to avoid a low tracheostomy without appropriate, and to proper fix the tracheostomy tube and try for early decannulation.

\section{Supplementary Information}

The online version contains supplementary material available at https://doi. org/10.1186/s43163-022-00211-3.

Additional file 1. Laser Machine details.

Additional file 2. The procedure was carried out under general anaesthesia using the intermittent apnoea technique (My Video).

\section{Acknowledgements}

No acknowledgements

\section{Authors' contributions}

Dr. N. S has operated these cases and written this article. Dr. A. S has done the data analysis. Dr.S. A has helped in getting the references. Dr. R. M has helped in the photographs of this case. The authors have read and approved the manuscript and ensure that this is the case.

\section{Funding}

None

Availability of data and materials

Data will be provided as and when required.

\section{Declarations}

\section{Ethics approval and consent to participate}

Ethics approval was waived by the Institutional Ethics Committee (IEC)-II Relating to Biomedical \& Health Research, Seth GS Medical College \& KEM Hospital, Mumbai (IEC(II)/OUT/735/2021). Informed written consent to participate in the study was provided by all participants.

\section{Consent for publication}

Informed written consent to publish was provided by all participants.

\section{Competing interests}

The authors have no conflict of interest to declare.

Received: 27 July 2021 Accepted: 11 October 2021

Published online: 22 February 2022

\section{References}

1. Kandakure VT, Mishra S, Lahane VJ (2015) Management of posttraumatic laryngotracheal stenosis: our experience. Indian J Otolaryngol Head Neck Surg 67(3):255-260. https://doi.org/10.1007/ s12070-014-0808-1

2. Grillo HC, Donahue DM, Mathisen DJ, Wain JC, Wright CD (1995) Postintubation tracheal stenosis. Treatment and results. J Thorac Cardiovasc Surg 109(3):486-492; discussion 492-3. https://doi.org/10.1016/S00225223(95)70279-2

3. Myer CM, O'connor DM, Cotton RT (1994) Proposed grading system for subglottic stenosis based on endotracheal tube sizes. Ann Otol Rhinol Laryngol 103(4):319-323. https://doi.org/10.1177/000348949410300410

4. Pearson FG, Andrews MJ (1971) Detection and management of tracheal stenosis following cuffed tube tracheostomy. Ann Thorac Surg 12(4):359374. https://doi.org/10.1016/S0003-4975(10)65137-5

5. Sarper A, Ayten A, Eser I, Ozbudak O, Demircan A (2005) Tracheal stenosis after tracheostomy or intubation: review with special regard to cause and management. Texas Hear Inst J 32(2):154-158

6. Pearson FG, Goldberg M, da Silva AJ (1968) Tracheal stenosis complicating tracheostomy with cuffed tubes. Clinical experience and observations 
from a prospective study. Arch Surg 97(3):380-394. https://doi.org/10 1001/archsurg.1968.01340030040002

7. Galluccio G, Lucantoni G, Battistoni P et al (2009) Interventional endoscopy in the management of benign tracheal stenoses: definitive treatment at long-term follow-up. Eur J Cardiothorac Surg 35(3):429-433. https://doi.org/10.1016/j.ejcts.2008.10.041

8. Softah A Rigid bronchoscopic dilatation of postintubation tracheal stenosis. West Afr J Med 24(3):234-238. https://doi.org/10.4314/wajm.v24i3. 28204

9. Noppen M, Schlesser M, Meysman M, D'Haese J, Peche R, Vincken W (1997) Bronchoscopic balloon dilatation in the combined management of postintubation stenosis of the trachea in adults. Chest 112(4):11361140. https://doi.org/10.1378/chest.112.4.1136

10. Balakrishnan K, Rutter MJ (2013) Balloon dilation of the airway

11. Colt HG, Dumon J-F (1993) Tracheobronchial stents: indications and applications. Lung Cancer 9(1-6):301-306. https://doi.org/10.1016/01695002(93)90685-Q

12. Grillo HC (1983) Tracheal surgery. Scand J Thorac Cardiovasc Surg 17(1):67-77. https://doi.org/10.3109/14017438309102383

13. Gardes J, Straker T (2012) Impossible Airway requiring venovenous bypass for tracheostomy. Case Rep Anesthesiol 2012:1-3. https://doi.org/ 10.1155/2012/592198

14. Gallagher TQ, Hartnick CJ (2012) Slide tracheoplasty. Adv Otorhinolaryngol 73:58-62. https://doi.org/10.1159/000334301

\section{Publisher's Note}

Springer Nature remains neutral with regard to jurisdictional claims in published maps and institutional affiliations.

\section{Submit your manuscript to a SpringerOpen ${ }^{\odot}$ journal and benefit from:}

- Convenient online submission

- Rigorous peer review

- Open access: articles freely available online

- High visibility within the field

- Retaining the copyright to your article

Submit your next manuscript at $\gg$ springeropen.com 